\title{
Bridging critical gaps in climate services and applications in africa
}

\author{
Tufa Dinku ${ }^{1 *}$, Paul Block², Jessica Sharoff ${ }^{1}$, Kinfe Hailemariam $^{3}$, Daniel Osgood ${ }^{1}$, John del Corral ${ }^{1}$, Rémi Cousin ${ }^{1}$ \\ and Madeleine C Thomson ${ }^{1,4}$
}

\begin{abstract}
Sound climate risk management requires access to the best available decision-relevant climate information and the ability to use such information effectively. The availability and access of such information and the ability to use it is challenging, particularly throughout rural Africa. A gap analysis published by the International Research Institute for Climate and Society (IRI) and the Global Climate Observing System (GCOS) in 2005 explored these challenges in detail and identified four key gaps: (i) gaps in integration of climate into policy; (ii) gaps in integration of climate into practice at scale; (iii) gaps in climate services; and (iv) gaps in climate data. Though this document was published nearly nine years ago, the gaps it highlighted are still relevant today. In the last decade, IRI has been making efforts to address these critical issues in a systematic way through projects and partnerships in Africa. This paper describes IRI's efforts in Ethiopia, a country particularly prone to climate related risks. Here we outline a creative solution to bridge the gaps in the availability, access and use of national climate information through the Enhancing National Climate Services (ENACTS) initiative. We then discuss how policy and practice has changed as a result of IRI engagement in the development of climate services in the water, public health and agricultural sectors. The work in Ethiopia is indicative of the efforts IRI is implementing in other countries in Africa and in other parts of the world.
\end{abstract}

Keywords: Climate services; Climate data; Hydropower; Malaria; Index insurance; Capacity building; Climate; Public health; Training; End users; Collaboration

\section{Background}

Availability of information ${ }^{\mathrm{a}}$ about past climate, recent trends, current conditions, likely future trajectories, and associated impacts is a prerequisite for climate-informed decision making. However, availability of relevant and reliable climate information, particularly throughout rural Africa, is substantially lacking (International Research Institute for Climate and Society 2006; Food and Agriculture Organization of United Nations 2008). Furthermore, both the quantity and quality of the limited amount of climate information provided by national meteorological services in Africa has been decreasing and deteriorating (Washington et al. 2006; International Research Institute for Climate and Society 2005). This basic lack of information and services has limited the use of climate information in development planning and practice in Africa (International Research

\footnotetext{
* Correspondence: tufa@iri.columia.edu

${ }^{1}$ International Research Institute for Climate \& Society (IRI), the Earth Institute at Columbia University, 61 Route 9 W, Monell Building, Palisades, New York, USA Full list of author information is available at the end of the article
}

Institute for Climate and Society 2006). It has also been a major obstacle to robust climate change research (Cooper et al. 2013).

Lack of climate information and services is not the only challenge. Lack of awareness about the existence of specific climate information, lack of understanding and capacity to use this information, reluctance to incorporate climate issues into management practices, and poor understanding of scientific uncertainties are other key impediments. Efforts must be made to improve the provision of climate information and services, and as well as integrate climate issues into development practices. In 2005, the International Research Institute for Climate and Society (IRI) led a "Gap Analysis" on how improvements in climate data and climate services could impact development outcomes in Africa (International Research Institute for Climate and Society 2006). The Gap Analysis identified four major areas for investment: 1) integration of climate information into policy; 2) integration of climate information into practice at 
scale; 3) improvement of climate services; and 4) improvement of climate data.

This paper presents examples of efforts in Africa by IRI and its partners to address these gaps in the water, public health and agricultural sectors. We provide case studies from Ethiopia - a country particularly susceptible to climate variability - to serve as examples of efforts being implemented throughout Africa as well as across the globe. The first section of this paper discusses the major accomplishments in improving data availability and climate services in Ethiopia through an initiative called Enhancing National Climate Services (ENACTS). The second section demonstrates the use of climate information in the water, health and agriculture sectors. For the water sector, we demonstrate the use of seasonal and long-term forecasts for hydropower dam planning and management. For the health sector, our case study shows the impact climate information can have on malaria prevention and control. Lastly, the agricultural sector example highlights how smallholder farmers can gain access to weather- based index insurance.

\section{Bridging gaps in climate data and services}

Since it was first established in 1980, Ethiopia's National Meteorological Agency (NMA) has collected, archived, analyzed climate information and disseminated derivative products to support socio-economic activities in in the country. The NMA has provided drought monitoring and early warning information for more than three decades (Broad \& Agrawala 2000; Hellmuth 2007). With over 1000 active observation stations, the NMA is one of the strongest national meteorological services (NMS) in Africa and has demonstrated a leadership role in a number of key developments. For instance, ten years prior to the development of the Regional Climate Outlook Fora in Africa (RCOFs, (Patt et al. October 2007)), the NMA was disseminating national seasonal climate forecasts. Despite these strengths, the data and services provided by NMA suffer from many shortcomings common to many NMSs in Africa, including the number and distribution of stations, data quality, missing observations, and problems with data access and use.

Although Ethiopia has a decent number of weather stations, with more added each year, the number of stations is still less than the minimum station density recommended by the World Meteorological Organization (WMO). In addition, the distribution of the available stations is very uneven (Figure 1). Most of the stations are located in cities and towns along the main roads. As a result, many stations are concentrated in the central highlands, with very few stations present in the lowlands. Existing records frequently suffer from data gaps and data quality problems. Another serious problem is that the available data is not used widely because it is not easily accessible outside the NMA. To address these challenges, the IRI embarked on an ambitious project with the NMA to improve the availability, access, and use of climate information in Ethiopia through the ENACTS initiative.

\section{Improving data availability}

Improving data availability requires addressing spatial and temporal gaps in existing climate observations as well as the quality of the data. One approach is combining station observations with satellite data and other proxies. Satellite rainfall estimates, which now go back over 30 years, are widely used in the absence of, or to supplement, ground station observations. The main strength of satellite products is that they provide good overall spatial coverage. However, these products have their own weaknesses, which include short record length, coarse spatial and temporal resolutions, inhomogeneity of the time series, and either poor or unknown accuracy. The ENACTS approach recently implemented at NMA integrates the spatial information from satellite and other proxies (such as elevation maps) with measurements from quality-controlled weather stations. This involves organization and quality control of the national archive of station data, selecting and processing satellite data, and combining the data from all stations (which pass a threshold in terms of quality and completeness) with satellites and other proxies. The combined data set is generated at a 10-daily time scale and for every $4 \mathrm{~km}$ grid across the country (Dinku et al. 2013).

To ensure temporal consistency of the satellite rainfall estimate, only thermal infrared (TIR) data from the METEOSAT satellite were used. Raw METEOSAT data going back to 1981 were obtained and processed by the TAMSAT (Tropical Application of Meteorology using Satellite and other Data) at the University of Reading in the UK. Then the TAMSAT rainfall retrieval algorithm (Grimes et al. 1999) was calibrated over Ethiopia using over 500 quality-controlled stations.

There is no reliable satellite temperature data going back 30 years. As a result, eleven-year averages (2003 to 2013) of the Moderate Resolution Imaging Radiometer (MODIS) land-surface temperature (LST) estimates were used along with digital elevation map (DEM) as a background to interpolate station temperature measurements. There are differences between land surface temperatures and the air temperature measured at meteorological stations. These differences are particularly significant for maximum temperature (Vancutsem et al. 2010). Despite these challenges experimentation indicated that the average MODIS-LST provides a good representation of the spatial variation of temperature. Regression Kriging (e.g. (Odeh et al. 1995; Hengl et al. 2004; Hengl et al. 2007)]) was used to merge rainfall measurements from 600 stations and temperature measurements from over 300 stations with satellite estimates and the digital elevation data. 


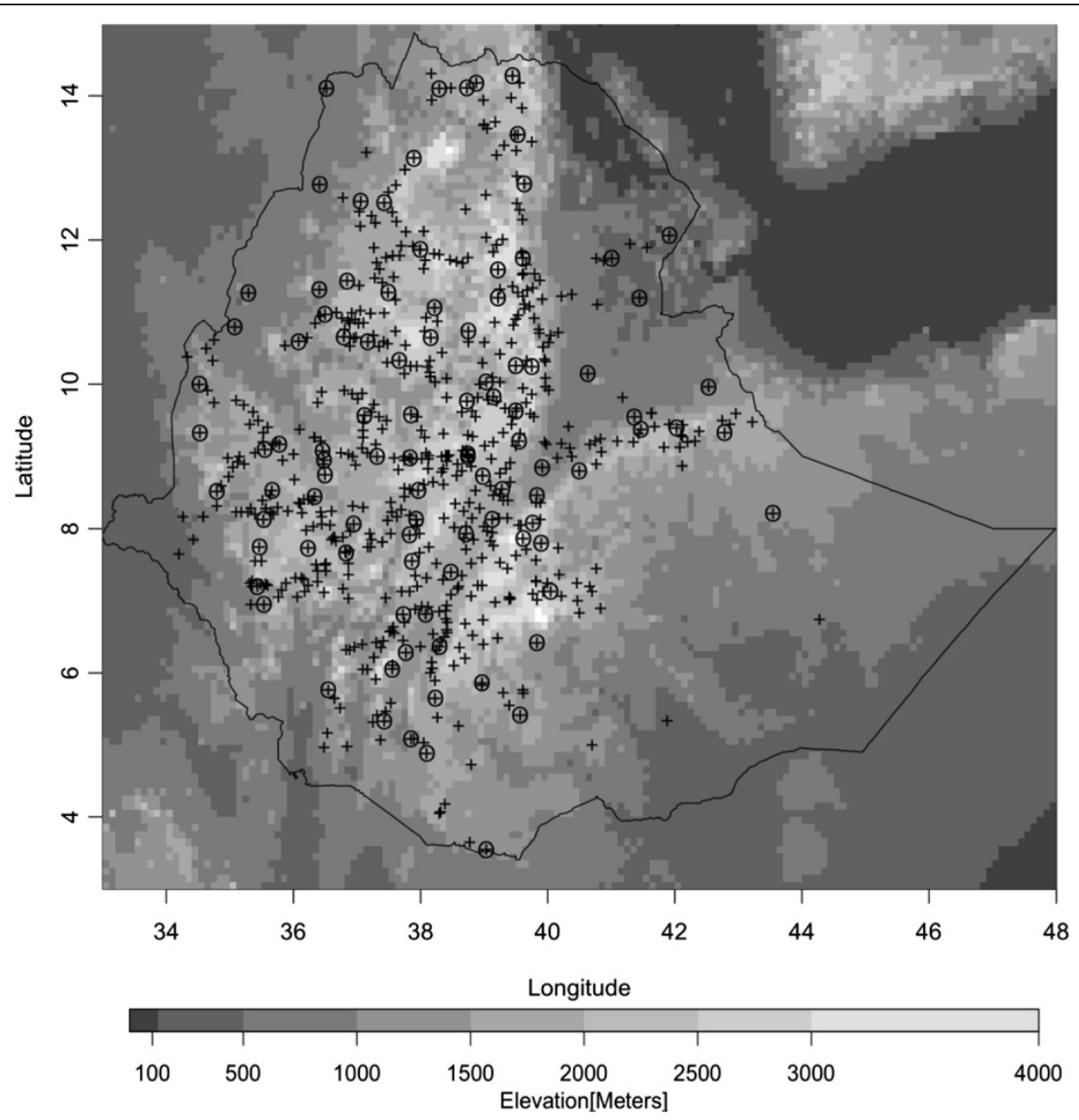

Figure 1 Distribution of raingauge stations used in the project. The background is elevation in meters. Note the lack of stations over the lowlands and how station locations follow roads.

The outputs of the ENACTS process are over 30-years of temporally and spatially complete rainfall and temperature time series data for every $4 \mathrm{~km}$ grid across Ethiopia. Figure 2 is a sample output for the $2^{\text {nd }}$ dekad (10 days) of June 2000 . The satellite product depicts the general spatial structure of the rainfall reasonably well, although it has a tendency to underestimate rainfall amounts. This underestimation is more prominent in areas with high rainfall amounts. The combined station and satellite product provide information at every location over the whole country and with a much higher degree of accuracy than satellite data alone. Figure 3 presents the merged product for minimum temperature. There are similarities between the elevation map and that of MODIS-LST, showing the strong dependence of temperature on elevation. The merged product combines the climatological information from elevation and MODIS with the current observation from the station measurements. Thus, it provides a better picture of the spatial structure of minimum temperature across the whole country.

\section{Improving access to climate information}

Even with the dramatic increase in availability of qualityassured climate data for the whole country, access to such data is constrained by technological and policy issues. To overcome these obstacles, access to climate information was improved by making derived products available through the Internet. This was achieved by improving the presentation of NMA products and services on their existing website and creating a 'Maproom' in which the new climate products could be viewed, manipulated and downloaded by anyone with an internet connection. This virtual Map Room currently comprises of three individual Map Rooms: Climate Analysis, Climate Monitoring, and Climate Forecast. The Climate Analysis Map Room provides information on the past climate at any location or for any administrative boundary. The Climate Monitoring Map Room is intended for monitoring the progress of the current season in terms of rainfall. The Climate Forecast Map Room, the first of its kind, presents information on the potential shift in rainfall as a function of El Niño 


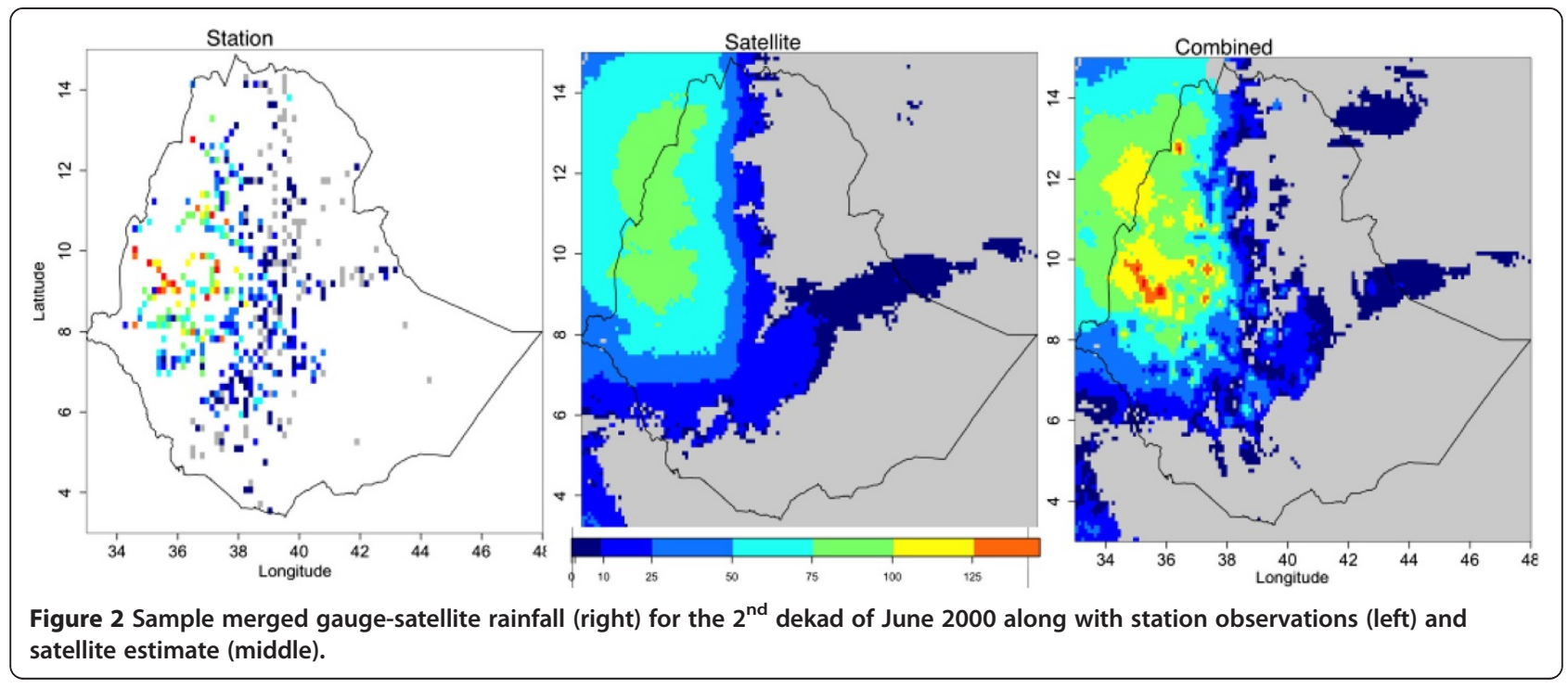

Southern Oscillation (ENSO) as well as presenting NMA's seasonal forecasts in the context of historical data. These Map Rooms were developed using the IRI Data Library tools, which has been installed at the NMA.

\section{Improving the of Use climate information}

Engaging users in the conceptualization of ENACTS, the definition of products (including initiating user oriented Map rooms for different sectors) and increasing their capacity to use the new products in decision making has not only helped the user community but has also provided a sense of direction and validation for the creation of climate services at the NMA. However significant limitations remain. In particular relying on web-based services of climate information may not be enough to reach all potential users due to limited Internet access in Ethiopia. Thus, the ENACTS work in Ethiopia needs further work, particularly in developing more user-specific products and in supporting users to understand and use the new and existing climate information products. However, what has been accomplished so far is extraordinary.

\section{Capacity development in the national meteorological agency}

NMA staff completed most of the ENACTS project work with IRI proving technical guidance and support. Thus, building NMA's capacity in areas relevant to this work was critical for making the work sustainable. As a result, a number of training workshops were given on-site at NMA. On-site training enabled participation of more trainees than would have been possible if the trainings were held outside the country. The training workshops were followed immediately with related work activities under the supervision of IRI staff. This helped to strengthen the knowledge acquired during the training workshops.
The IRI is still providing technical support to the NMA on an as-needed basis.

\section{Uptake of the Ethiopia experience}

The information products provided by NMA, though basic, are unprecedented in Africa, and in fact many other parts of the developing world. Therefore, the Ethiopian experience could serve as a template to improve climate services across Africa. Following requests from other meteorological and development agencies, ENACTS has already been implemented in the national meteorological agencies of Tanzania and Madagascar, as well as at regional level in West Africa in collaboration with the AGRHYMET Centre. Work has also started in Rwanda, where there is about 15-year observation gap following the 1994 genocide. Plans are also underway to implement ENACTS in more countries and establishing long-term sustainability of the initiative is now a priority.

\section{Bridging the gaps in policy and practice.}

Improving the availability and access to climate information is important but will have little impact on reducing climate related risks to national development if policies are insensitive to climate information and development practitioners are unable or unwilling to use such information in decision-making. Below we describe three examples where climate information is being explored for sectoral applications in Ethiopia.

Use of climate information for hydropower operations Ethiopia is embarking on an ambitious energy development strategy, leaning heavily on their abundant hydropower potential, of which only $10 \%$ has been harnessed. Optimal operational strategies and adequate planning for a changing climate, including uncertainty in water supply, will be 

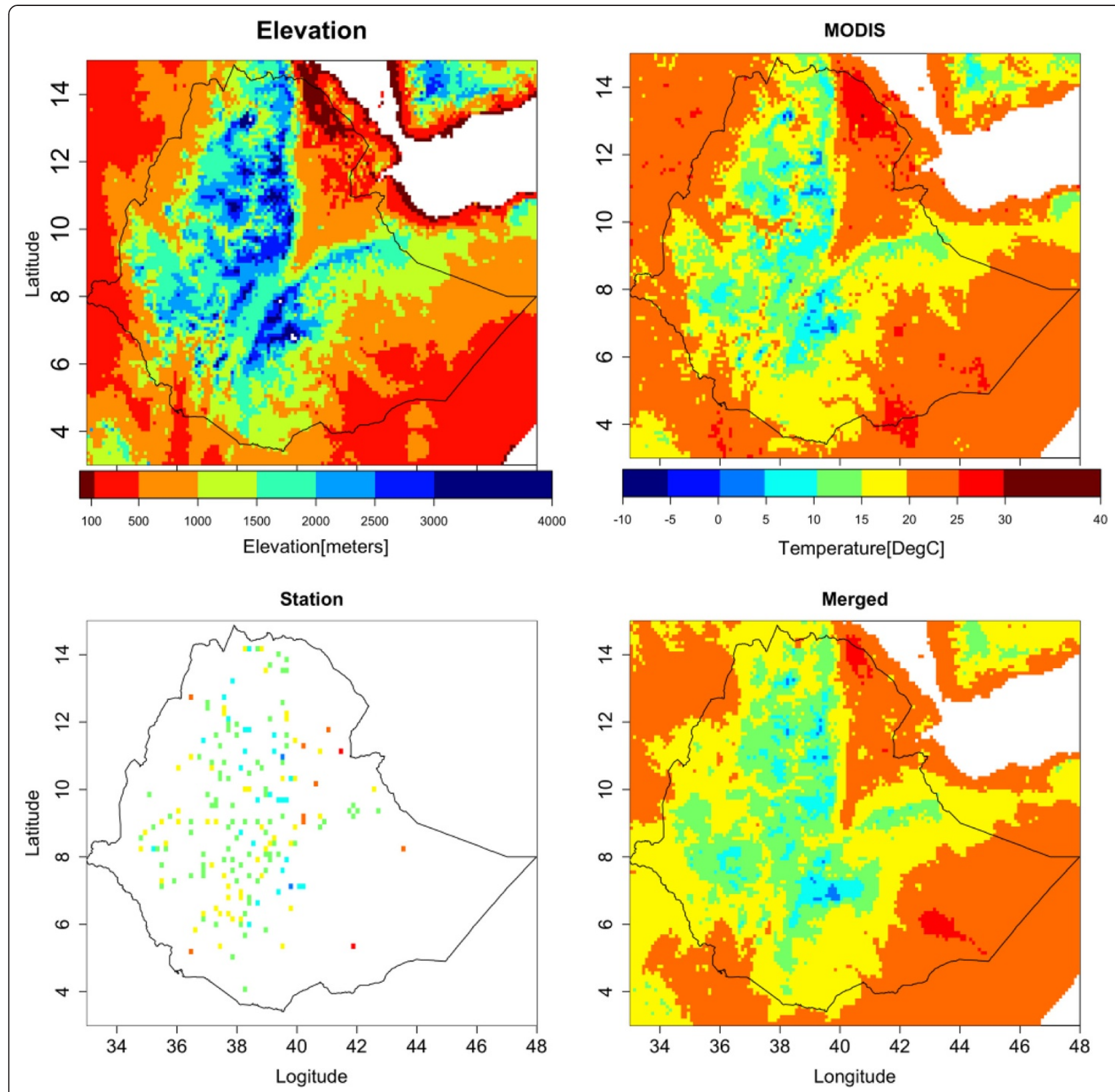

Figure 3 Merged minimum temperature (lower right) for the $2^{\text {nd }}$ dekad of April 2000 along with elevation map (top left), 10-year MODIS average (top right), and station measurements (lower left).

critical to meeting future expected targets. IRI's work in Ethiopia bridges the modeling gaps between climate, energy, and economics to effectively transform climate information into economic measures, at both the seasonal and long-term scales.

\section{Seasonal forecast development and application to hydropower operations}

As part of Ethiopia's energy development strategy, four large-scale hydroelectric dams along the Blue Nile have been proposed (Figure 4). Once installed and operational, these dams may have upwards of 10,000 megawatts of power potential. From an operational management perspective, climate predictions with lead times of one season or more are attractive in that they could provide advance information to guide storage and release decisions, potentially improving energy benefits (or equivalently, minimizing losses) and reliability. This motivates assessing hydropower benefits based on integrating a seasonal forecast, compared with a no-forecast approach, in which decisions are based on existing conditions and climatology. 


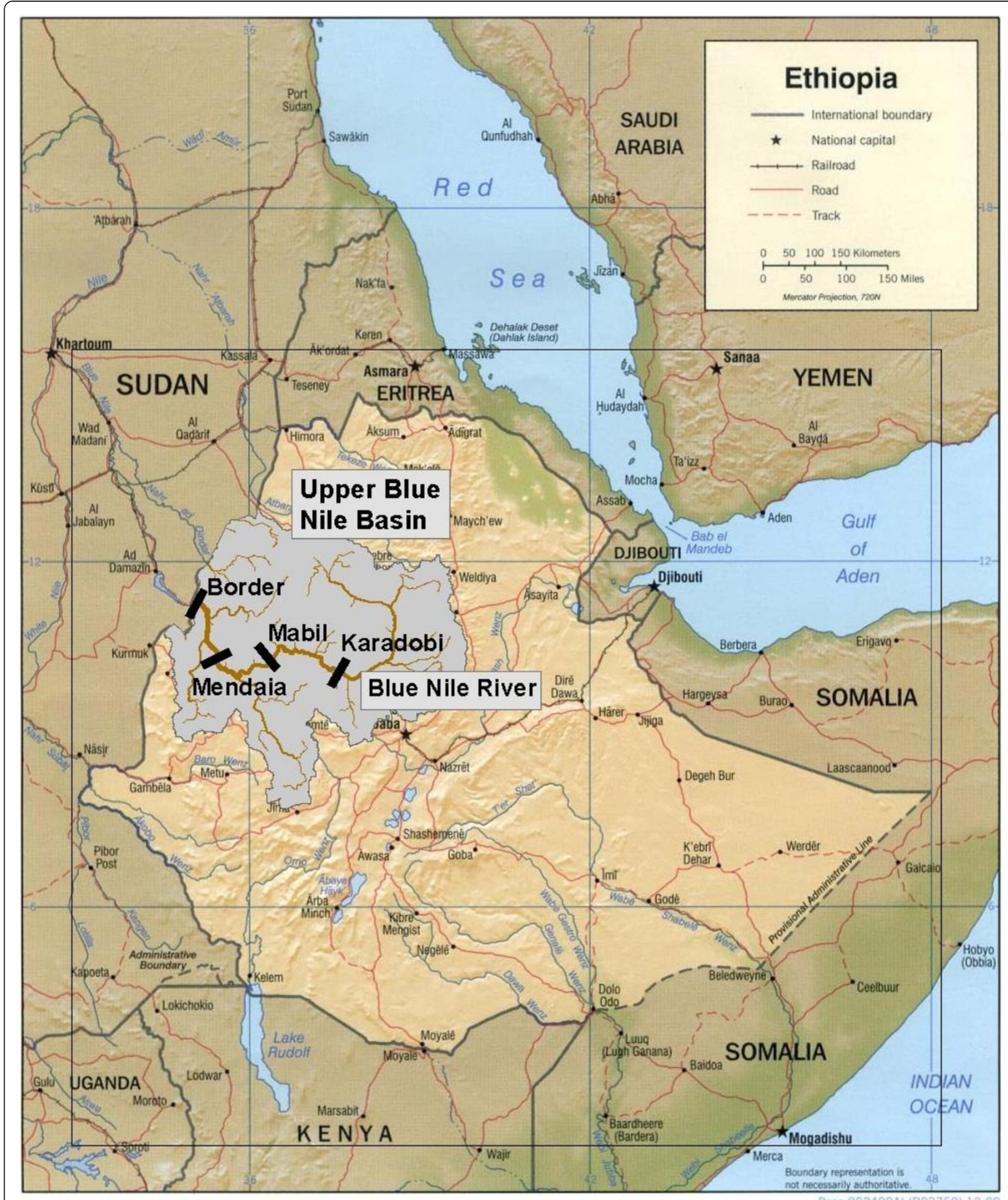

Figure 4 The upper Blue Nile basin, Ethiopia, including proposed large-scale hydropower dams. Base map courtesy of the Perry-Castaneda Library map collection, University of Texas. Figure from (Block 2011). 
Three major system components are required: the precipitation forecast, a rainfall-runoff model to produce streamflow and evaporation, and the hydropower management model to compare benefits from forecast and noforecast approaches (Block 2011; Block \& Goddard 2012). Results from extensive simulations indicate that although hydropower benefits based on the no-forecast approach are not drastically inferior to benefits derived from a forecast-based approach, a number of no-forecast simulations produce notably low benefits. The elimination of these with the forecast-based hydropower system is promising, and may begin to entice managers to incorporate such methodologies into their practices.

Ideally, these types of illustrations can provide decision makers with incentives to integrate improved prediction techniques into sectoral management models, and further justify expanding efforts into climate forecast improvement. Seasonal precipitation forecasts are regularly published by NMA on their website; however, they are not necessarily tailored for hydropower management and would benefit from improved verification using the ENACTS products highlighted above. The Ethiopian Electric Power Company (EEPCo) occasionally requests NMA's input, but there is no vetted systematic approach currently in place to address such requests. Given seasonal forecast prospects, moving toward such an approach seems plausible and attractive.

\section{Climate change and long-term energy development}

Ethiopia has defined an ambitious energy development plan, motivating an analysis to understand how and to what extent climate change may impact the energy sector through hydropower (Block \& Strzepek 2012).

The framework to evaluate energy production consists of a linked climate-hydrology-hydropower system capable of transforming climate change information into potential energy production, much the same as the system developed for the seasonal forecast approach. Climate changes are based on the U.S. Geophysical Fluid Dynamics Laboratory's general circulation model (GCM) for the A1b scenario. This GCM produces the national driest averages of all GCMs evaluated, as determined by the climate moisture index averaged across the 2045-2055 decade (Robinson et al. 2011).

To create climate change simulations, the overall precipitation trend from the GCM for 2010-2050 is extracted and added to the monthly 1960-2000 observations. To partially capture uncertainty arising from inter-annual variability, a simple stochastic approach is adopted. Twenty unique sequences are constructed by bootstrapping and assembling forty years of monthly values from the historical 1960-2000 record and added to the same 2010-2050 GCM precipitation trend. Upon processing these timeseries through the linked system, representing Ethiopia's long-term strategic energy development plan, energy production illustrates a potentially sizeable spread (Figure 5). Total energy production summed over 2010-2050 varies from 1242 - 1358 terawatt (TW)-hours; total energy production at the end of the period varies from $36-63 \mathrm{TW}$ hrs (Ministry of Water Resources, UNESCO, GIRDC 2004).

This type of research is a starting point for bridging the modeling gaps between climate, energy, and economics to guide development and planning. The outcomes can also serve as inputs to a wider economic analysis to better understand feedback and cross-sectoral influences of hydropower development.

\section{Capacity development}

IRI has developed and delivered trainings focused on managing hydroclimatic risk in the water sector to facilitate education, capacity building, and potential use of climate information in decision models. These trainings have targeted Ethiopian water resource professionals, predominantly those serving at the Ministry of Water and Energy, with expert presenters from climate, remote sensing, and water management disciplines.

Two important non-technical outcomes surfaced from the trainings. First, some component of management decision making in East Africa is intrinsically tied to religious and/or cultural beliefs. While the science may be well understood and accepted, the social influences cannot be ignored. Working within the cultural context is crucial. Secondly, perverse incentives to not use forecasts exist. Upon completion of one training, the presenter asked the participants if they grasped the importance of climate risk management, particularly forecasts, if they

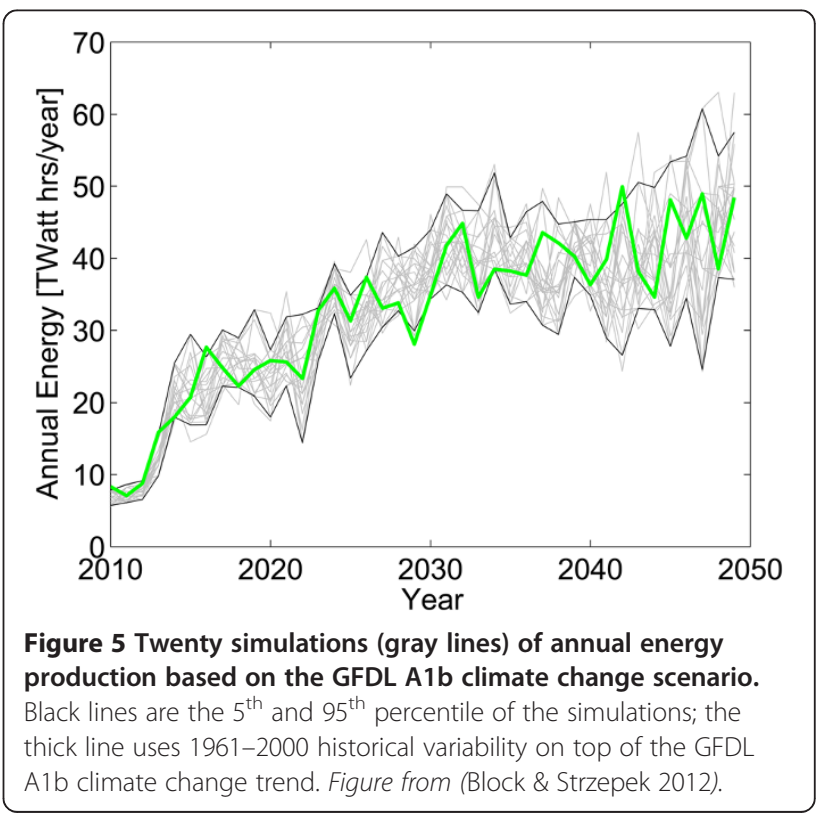


realized benefits in its application, and if they understood how it could be integrated into a system of models to inform management decisions. All participants nodded affirmatively. The follow-up question of whether they would immediately and explicitly include climate forecasts and projections into their own operations was met with an unambiguous "no." After some prodding, it became clear that water managers considered the use of a probabilistic forecast, with the potential to be "wrong", as a personal liability. Presently, this is a critical institutional barrier, not unique to East Africa, deserving of attention from policy makers and high-level decision makers, to design measures for transferring this risk away from the manager.

\section{Impact assessment of malaria control interventions}

IRI has been extensively involved in climate and health activities in Africa (Omumbo et al. 2011). As a World Health Organisation Collaborating Center for malaria early warning and other climate sensitive diseases, IRI has particularly focused on the use of climate information in malaria risk mapping (Ceccato et al. 2007), early warning (Thomson et al. 2006) and impact assessment - see below.

Since 1998, when Roll Back Malaria (RBM) was initiated, hundreds of millions of dollars have been spent by national governments, non-governmental organizations and international donor community to reduce the burden of malaria in Africa, estimated to cause between 500,000-1 million deaths annually (WHO/UNICEF 2013). A key recipient of external resources and government support is the Ministry of Health in Ethiopia, where investments in malaria control have reached record levels (Presidents Malaria Initiative (PMI) 2012).

\section{Malaria control in Ethiopia}

Malaria in Ethiopia is extremely climate sensitive with the majority of the population living in regions prone to climate-related epidemics (Abeku et al. 2003). In this climatologically complex country, the determinants of malaria transmission are diverse and localized. For example, temperature (especially minimum temperature), which is linked to altitude, is a major limiting factor for malaria transmission in the highland plateau region (Abeku et al. 2003), as is rainfall in the semi-arid regions. When substantial climate variations occur, malaria epidemics can develop rapidly, with devastating effects. Other factors such as population displacement, land-use change, and drug and insecticide resistance may also play an important role (Abeku et al. 2003).

Since 2005, there has been a dramatic increase in malaria interventions in Ethiopia. Currently, the Federal Ministry of Health and its development partners are seeking to assess the impact of these interventions on all-cause mortality, as well as malaria-specific morbidity and mortality (Otten et al. 2009). Since 2010, the PMI has used Roll Back Malaria's methodology to evaluate its malaria interventions (Roll Back Malaria Partnership (RBM) 2011). The methodology identifies the need to explain contextual and/or confounding factors (e.g. urbanization, agricultural development, education, burden of other infectious disease, etc.) that may have had an impact on malaria transmission during the past six years of intervention activities.

In order to remove the confounding effect of climate, high-quality climate information is needed at the appropriate temporal and spatial scale. NMA's new ENACTS data and products, described above, provide an opportunity to improve the impact assessment of malaria interventions in Ethiopia and to train key stakeholders in the use of climate information in malaria control in general.

\section{Impact assessment}

Given the spatio-temporal nature of climate variability and change across very varied epidemiological setting, the careful use of routine health surveillance data along with sentinel site information in the impact analysis of malaria intervention has become increasingly important (Jima et al. 2012) despite major concerns with regard to the quality of the surveillance data. In a project funded by the PMI entitled "Development of Climate Analysis Section for the President's Malaria Initiative Impact Evaluation: Reports for Ethiopia and Tanzania", the IRI worked with partners in Ethiopia to develop methodologies and tools for the incorporation of the new climate information into malaria impact assessments (Thomson et al. 2012). The new ENACTS rainfall and temperature products disseminated by the NMA have been used for analysis at both national and sub-national levels (region, zone, woreda). A simple climate analysis tool was created to provide information on anomalies in rainfall and temperature relative to a long-term mean by administrative boundary. This information can be used to assess the likelihood that climate was a confounder in the analysis of the impact of malaria interventions (Jima et al. 2012). For example, the Oromia Region of Ethiopia is home to approximately $35 \%$ of Ethiopia's people and is the source of more than a third of the country's confirmed malaria cases (Presidents Malaria Initiative 2013). Recent climate trends for the region's two rainy seasons, the Belg and Meher (Kiremt) are set out below (Figure 6). Substantial warming can be observed over this large and complex region in both seasons over the time period 1983-2010. This warming may make highland regions more susceptible to malaria. An extended drought period from 1997-2009 for the Belg season can also be observed. The conclusion for this region (and Ethiopia in general) was that the pre-intervention period (2000-2005) was both drier and cooler (and thereby less favorable to malaria) than the post intervention period (2006-2010). 

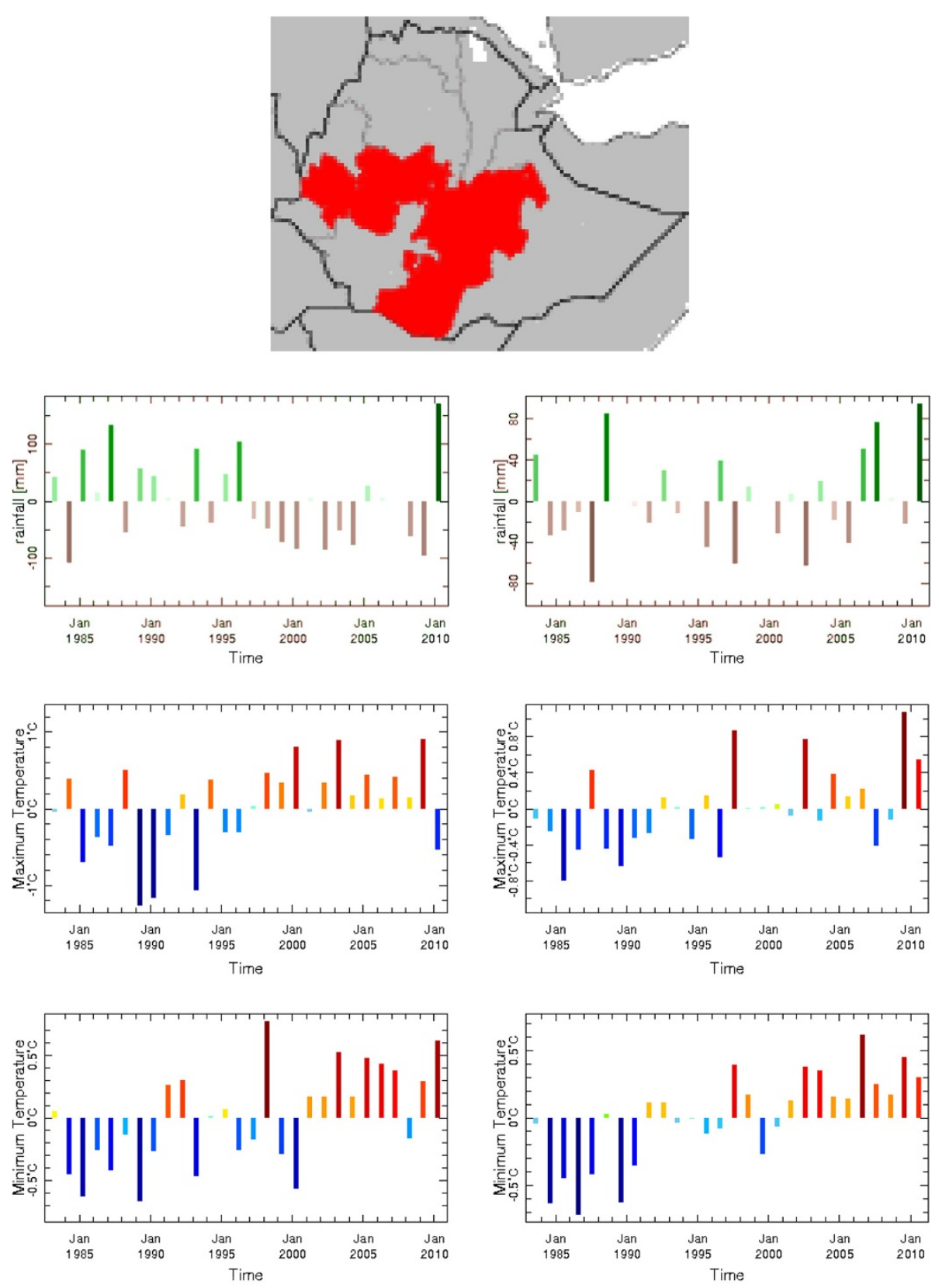

Trend in rainfall (top) max $\mathrm{T}$ (middle) and min T (bottom) for

Trend in rainfall (top) max $\mathrm{T}$ (middle) and min $\mathrm{T}$ (bottom) for the Belg rainy season (Feb-May).

the Kiremt rainy season (Jun-Sep)

Figure 6 Output from the Climate Analysis tool for Oromia region of Ethiopia (similar information is available for all regions, zones and woredas).

Thus, any observed decline in malaria during the 20062010 period could not be attributed to a decline in climate suitability for transmission.

\section{Capacity development}

Building capacity to use climate information in malaria impact assessments is critical to the approach being developed. A training workshop, held in Ethiopia with participants from the Ministry of Health, the School of Public Health, NGOs and international agencies demonstrated the feasibility of the approach (Getinet et al. 2011). A similar approach was used in the analysis of the impact of malaria interventions in Tanzania (Dinku et al. 2014). 


\section{Bringing index insurance to smallholder farmers Index insurance: opportunities and challenges}

Climate variability and change, if not properly accounted for, can act to amplify poverty and depress livelihoods, especially for vulnerable populations (Intergovernmental Panel on Climate Change (IPCC) 2007). Index insurance is a potential tool for both managing climate risks and enabling productive opportunities in the agriculture sector (Hellmuth 2009; Hazell et al. 2010). It provides farmers with insurance coverage based on an index-such as wind speed or an amount of rain. Payouts are triggered when the index passes a specified threshold, and are not based on observed crop loss (like traditional "indemnity" insurance). This can help resolve a number of fundamental problems that often make traditional crop insurance unworkable in rural parts of developing countries (World Bank 2011). In principle, index-based products might lower an insurance company's costs, potentially reducing premiums and reaching new farmers.

While offering efficiency and simplicity compared to traditional insurance, designing successful index insurance programs has proven to be challenging (Brown et al. 2011; Osgood \& Shirley 2012). It is essential to base an index on objective data for which there is a historical record, and that closely correlates to loss. In addition, the most accurate calculation of insurance payouts based on index measurements (e.g. rainfall, wind, or other quantities) will always have some level of disagreement with actual losses on a real farm. This is because what the index captures may be different than what is happening on each farm, farmers' losses may be caused by something that was not covered by the insurance, and correlations are never perfect (Hazell et al. 2010).

While there are significant challenges in applying index insurance, because of its benefits many look to it as the first opportunity to bring agricultural insurance to numerous vulnerable populations (Schwank et al. 2010). In order for insurance to be valuable enough to be purchased by these farmers and safe enough to be responsible, solutions must allow some of the poorest farmers in the world to interact with advanced researchers at a sophisticated level. This challenge is impossible without being able to depend on advanced climate services, of which capacity development is a significant component.

\section{The $R 4$ rural resilience initiative: overcoming challenges in Ethiopia}

The R4 Rural Resilience Initiative, launched by Oxfam America and the World Food Program, is a climate change resiliency project (Osgood 2012). As part of the R4 project in Ethiopia ${ }^{\mathrm{b}}$, IRI collaborates with local partners and farming communities to develop and provide rainfall-based index insurance for farmers. This project relies heavily on a foundation of climate services that IRI has helped develop in East Africa to enable end-user driven processes. The participation of local NGOs (e.g. Relief Society of Tigray), government agencies (e.g. Ethiopian Ministry of Agriculture, Ethiopian NMA), financial institutions and farmer communities is central to these efforts.

The insurance project relies on multiple sources of climatological information, in addition to local expert and farmer agro-ecological experience. The project uses the Africa Rainfall Climatology (ARC) satellite rainfall estimates, produced by NOAA-CPC ${ }^{\mathrm{C}}$, to design and trigger index insurance contracts. IRI also facilitates access to ARC, through the Data Library and other agro-ecological information that has been critical in refining and validating these indexes. Other satellite-based climatological products (e.g. ENACTS), as well as the NMA's rain gauge network and local farmer-based raingauges are used to verify that existing indices accurately capture local drought conditions experienced by farmers (Osgood 2012).

While climate information is a critical aspect in the insurance project, this work is not possible without high quality climate services that connect the climate information with practical applications on-the-ground. The project relies on two-way communication between international and local technical experts, scientists, and farmers, allowing farmers to have direct access to climate information and climate experts to have direct access to farmer knowledge and needs (Sharoff et al. 2012).

Through IRI's capacity development processes (Mantilla et al.), including the Social Network for Index Insurance Design (SNIID) platform, community design teams in each village work with project partners to verify the accuracy of historical meteorological and agricultural data based on recollections of their own experiences with drought (Norton et al. 2013). Farmers help identify the risks and vulnerabilities that they face, which cannot be appropriately addressed through other risk reduction means. Each design team provides feedback on which crops and times of year it is most important to have index insurance coverage. The farmers also make decisions about the amount and types of payouts that would have been appropriate in the past. Using historical information to set a precedent for the future, they describe under which type of historical conditions an insurance payout would have made a significant difference in their coping strategies. This dialogue ensures that farmers and project partners have collaborated directly and on equal footing to collect and customize information to create insurance packages that try to address the specific climate and production risks that each region faces.

\section{Capacity development}

Capacity development is a critical component of climate services and tightly knit into the processes described 
above. Allowing all stakeholders to provide input, be involved in project decision-making, and participate in a collaborative demand-driven process is essential for the application of climate information towards robust index design. In the R4 Ethiopia project, in order for local stakeholders to provide valuable information and feedback regarding the development and design of potential indices, they needed a deeper understanding of index insurance, satellite-based rainfall indices, and the relevant climate science. Farmers in particular wanted to learn more about the project, so that they could make more informed decisions on whether index insurance is an appropriate tool for them and how it could be tailored to better meet their needs.

To meet these needs, IRI created an index insurance capacity development process built on three main components: 1) trainings regarding index insurance, climate risk management and climate information, 2) facilitation of information sharing, and 3) collaborative development and tailoring of capacity building materials for different audiences (primarily farmers), so that local partners can create their own capacity development, design, and implementation processes (Mantilla et al.). This approach to capacity development consists of two-way information sharing sessions; hands-on exercises using real case study data; playing through scenarios ("games"); trainings using Weather Index Insurance Educational Tool (WIIET) - a climate service tool created and provided by IRI to teach users how to design, refine, and analyze index-based insurance, taking into account farmer input alongside the instrumental records and guidance on how to access, use and interpret freely available climate data online through IRI's Data Library and Map Room. These activities are used to help participants explore the main concepts of index insurance and climate risk management, as well as to facilitate a collaborative index design process.

This approach has enabled index insurance programs like R4 Ethiopia to grow dramatically, scaling from 200 farmers transactions in 2009 to over 19,000 in 2012 (Oxfam 2013a). There is a substantial amount of effort underway to understand the quality of coverage and impacts of these indexes (International Research Institute for Climate and Society, Columbia University 2013; Chen et al. 2010; Oxfam 2013b). Since yield data (and other data) is so sparse across this region, participatory processes are central to this effort.

The insurance project partners have joined forces to launch a global R4 effort and build on the Ethiopia model for climate services, participatory design, and capacity development. Expansion of the project is already being seen within Ethiopia, as well as in Senegal (International Research Institute for Climate and Society 2012). It is also expected to scale to two other countries within the next five years. Outside of the R4 system, IRI is using similar strategies to enable index insurance processes throughout Africa, including Kenya, Uganda, and Tanzania.

\section{Summary}

The IRI has been making strenuous efforts to fulfill its mission of "enhancing society's capability to understand, anticipate and manage the impacts of climate," in different regions of the developing world. As demonstrated in the ENACTS initiative and the three sectoral case studies highlighted above, these efforts include significant progress in enhancing the generation, dissemination, and effective use of climate information in different sectors in Ethiopia. The ENACTS initiative has helped in improving the availability and accessibly of reliable climate information for decision-making. The sectoral examples have demonstrated the potential use of climate information. Sustainability of the work is ensured through transfer of knowledge by training and involving national experts in the work.

The IRI has taken an end-user focused approach to collaboratively create climate services in Ethiopia. However, considerable work remains to be done towards facilitating the better use of data and information products. Meteorological agencies must demonstrate that the ENACTS products are a "gold standard" combining the best local and global data sources and can be produced routinely in a sustainable manner, that new data can be routinely added to the historical archive, that the data, methodologies and tools used can be regularly improved by the national staff themselves and that the new products can be created from thses resources in response to user needs. While this is critical, data and services are not the only gaps. Lack of capacity to use climate information and policies that limit the application of probabilistic climate information continue to constrain the impact of innovations in climate services. Much remains to be done before climate information plays out to its full potential in reducing climate related risks.

\section{Endnotes}

${ }^{a}$ Climate information here refers to climate data and derived products.

${ }^{\mathrm{b}} \mathrm{R} 4$ is formally known as the Horn of Africa Risk Transfer for Adaptation (HARITA) project in Ethiopia.

${ }^{c}$ http://www.cpc.ncep.noaa.gov/products/fews/AFR_CLIM/AMS_ARC2a.pdf

Competing interests

The authors declare that they have no competing interests.

\section{Author's contributions}

$\mathrm{TD}, \mathrm{KH}, \mathrm{RC}$ and JdC worked on the ENACTS project in Ethiopia and TD also contributed the section on bridging gaps in climate data and services. PB contributed the section on use of climate information for hydropower operations while MCT wrote the sections on impact assessment of malaria control interventions. JS and DO wrote the section on bringing index insurance to smallholder farmers. All authors read and approved the final manuscript.

\section{Acknowledgement}

The initial work to improve climate serves in Ethiopia was funded by Google. org and a grant/cooperative agreement from the National Oceanic and 
Atmospheric Administration, NA050AR4311004. The views expressed herein are those of the authors and do not necessarily reflect the views of NOAA or any of its sub-agencies.

Responsible editor: Krishna Kumar Kanikicharla

\section{Author details}

${ }^{1}$ International Research Institute for Climate \& Society (IRI), the Earth Institute at Columbia University, 61 Route 9 W, Monell Building, Palisades, New York, USA. ${ }^{2}$ University of Wisconsin- Madison, 1415 Engineering Drive, Madison, Wisconsin, USA. ${ }^{3}$ National Meteorology Agency, P.O.Box 1090, Addis Ababa, Ethiopia. ${ }^{4}$ Department of Environmental Health Sciences, Mailman School of Public Health, Columbia University, New York, USA.

Received: 1 October 2013 Accepted: 10 April 2014 Published: 17 June 2014

\section{References}

Abeku TA, van Ooortmarssen GJ, Borsboom G, de Vlas SJ, Habbema JDF (2003) Spatial and Temporal Variations of Malaria Epidemic Risk in Ethiopia: Factors involved and implications. Acta Trop 87(3):331-340

Block P (2011) Tailoring seasonal climate forecasts for hydropower operations. Hydrol Earth Syst Sci 15:1355-1368

Block P, Goddard L (2012) Statistical and Dynamical Climate Predictions to Guide Water Resources in Ethiopia. J Water Resour Plan Manag 138(3):287-298

Block P, Strzepek K (2012) Power Ahead: Meeting Ethiopia's Energy Needs Under a Changing Climate. Rev Dev Econ 16(3):476-488

Broad K, Agrawala S (2000) The Ethiopia Food Crisis-Uses and Limits of Climate Forecasts. Science 289(5485):1693-1694

Brown ME, Osgood DE, Miguel CA (2011) Science-Based Insurance. Nature GeoScience 4:213-214

Ceccato P, Ghebremeskel T, Jaiteh M, Graves PM, Levy M, Ghebreselassie S, Ogbamariam A, Barnston AF, Bell M, del Corral J, Connor SJ, Fesseha I, Brantly EP, Thomson MC (2007) Malaria stratification, climate, and epidemic early warning in Eritrea. Am J Trop Med Hyg 77(6):61-68

Chen J, Dinku T, Holthaus E, Lyon B, Madajewicz M, Mullaly C, Norton M, Osgood D, Pascualini A, Pant S, Peterson N, Saavedra R, Sharoff J, Shirley KE, Small C, Stiffel S, Teh TL (2010) HARITA IRI Report to Oxfam America: Final Report for IRI MIEL Planning and Technical Support for HARITA Micro-Insurance Pilot. IRI Technical Report, pp 08-10

Cooper PJM, Stern RD, Noguer M, Gathenya JM (2013) Climate Change Adaptation Strategies in Sub-Saharan Africa: Foundations for the Future. In: Sigh RH (ed) Climate Change - Realities, Impacts Over Ice Cap, Sea Level and Risks. Intech, Rijeka, pp 327-356

Dinku T, Hailemariam K, Maidment R, Tarnavsky E, Conner S (2013) Combined Use of Satellite Estimates and Raingauge Observations to Produce High-Quality Historical Rainfall Time Series Over Ethiopia. Int J Climatology 10.1002/joc.3855

Dinku T, Kanemba A, Mandike R, Platzer B, Thomoson MC (2014) Leveraging the Climate for Improved Malaria Control in Tanzania. In: Earthzine Special Issue on "Earth Observations for Health. [http://www.earthzine.org/2014/02/15/ leveraging-the-climate-for-improved-malaria-control-in-tanzania/]

Food and Agriculture Organization of United Nations (2008) Climate change and food security: A framework document Rome

Getinet Y, Miheretie A, Thomson M (2011) The use of Climate Information in Impact Assessment for Malaria Interventions. Workshop Report. Climate and Health Working Group of Ethiopia, Addis Ababa

Grimes DIF, Pardo E, Bonifacio R (1999) Optimal areal rainfall estimation using raingauges and satellite data. J Hydrol 222:93-108

Hazell P, Anderson J, Balzer N, Clemmensen A, Hess U, Rispoli F (2010) The Potential for scale and sustainability in weather index insurance for agriculture and rural livelihoods. IFAD, Rome

(2007) Climate Risk Management in Africa: Learning from Practice. Hellmuth ME Moorhead A, Thomson MC, Williams J (ed) International Research Institute for Climate and Society (IRI).

(2009) Index insurance and climate risk: Prospects for development and disaster management. In: Hellmuth ME, Osgood DE, Hess U, Moorhead A, Bhojwani H (ed) Climate and Society. No. 2 International Research Institute for Climate and Society, New York
Hengl T, Heuvelink GMB, Stein A (2004) A generic framework for spatial prediction of soil variables based on regression kriging. Geoderma 122:75-93

Hengl T, Heuvelink GBM, Rossiter DG (2007) About regression-kriging: From equations to case studies. Comput Geosci 33:1301-1315

Intergovernmental Panel on Climate Change (IPCC) (2007) Fourth assessment report. Geneva

International Research Institute for Climate and Society (2005) Sustainable development in Africa: Is the climate right? IRI Technical Note No. IRI-TR/05/1, New York

International Research Institute for Climate and Society (2006) A Gap Analysis for the Implementation of the Global Climate Observing System Programme in Africa. IRI Technical Report No. IRI-TR/06/1, New York

International Research Institute for Climate and Society (2012) Poor Ethiopian Farmers Receive "Unprecedented" Insurance Payouts. IRI press release http://iri.columbia.edu/docs/features/2012_spotlight_features/ poor_ethiopian_farmers_receive_unprecedented_insurance_payout.html International Research Institute for Climate and Society, Columbia University (2013) Using Satellites to Make Index Insurance Scalable: Final IRI Report to the UN ILO Microinsurance Innovation Facility. IRI Technical Report

Jima D, Wondabeku M, Alemu A, Teferra A, Awel N, Deressa W, Adissie A, Tadesse Z, Gebre T, Mosher A, Richards F, Graves P (2012) Analysis of malaria surveillance data in Ethiopia: what can be learned from the integrated disease surveillance and response system? Malar J 5(17):330

Mantilla G, Thomson C, Sharoff J, Barnston A, Curtis A: (2014) Capacity development through the sharing of climate information with diverse user communities. Earth Perspect 1:21

Ministry of Water Resources, UNESCO, GIRDC (2004) National Water Development Report for Ethiopia. UNESCO World Water Assessment Program, Addis Ababa

Norton MT, Turvey C, Osgood D (2013) Quantifying spatial basis risk for weather index insurance. The Journal of Risk Finance 14(1):20-34

Odeh I, McBratney A, Chittleborough D (1995) Further results on prediction of soil properties from terrain attributes: heterotopic cokriging and regression-kriging. Geoderma 67:215-226

Omumbo J, Platzer B, Girma A, Connor SJ (2011) Climate and Health in Africa: 10 Years On Workshop, Addis Ababa, Ethiopia. IRI Technical Report 11-01. IRI New York

Osgood D (2012) Geospatial Data in Agriculture Risk Management: the IRI Index Insuarnce Experience. Forum for Agricultural Risk Management in Development (FARMD). [https://www.agriskmanagementforum.org/content/ geospatial-data-agriculture-risk-management-iri-index-insurance-experience]

Osgood D, Shirley KE (2012) The Value of Information in Index Insurance for Farmers in Africa. In: Laxminarayan R, Macauley MK (ed) The Value of Information. Springer, Netherlands, pp 1-18

Otten M, Aregawi M, Were W, Karema C, Medin A, Bekele B, Jima D, Gausi K, Komatsu R, Korenromp E, Low-Beer D, Grabowsky M (2009) Initial evidence of reduction of malaria cases and deaths in Rwanda and Ethiopia due to rapid scale-up of malaria prevention and treatment. Malar J 8:14

Oxfam (2013a) R4 Rural Resilience Initiative. Quarterly Report, Oxfam America

Oxfam (2013b) R4 Rural Resilience Initiative. Quarterly Report, Oxfam America. in press

Patt AG, Ogallo L, Hellmuth M (October 2007) Learning from 10 Years of Climate Outlook Forums in Africa. Science 5:49-50

Presidents Malaria Initiative (2013) Malaria Operational Plan (MOP) Ethiopia FY 2012. Addis Ababa

Presidents Malaria Initiative (PMI) (2012) Malaria Operational Plan (MOP) Ethiopia FY 2012. Addis Ababa

Robinson S, Strzepek K, Willenbockel D (2011) Adaptation to Climate Change in Ethiopia. Rev Dev Econ 16:489-502

Roll Back Malaria Partnership (RBM) (2011) A decade of partnership and results. Progress and Impact Serie, Washigton DC

Schwank O, Steinemann M, Bhojwani H, Holthaus E, Norton M, Osgood D, Sharoff J, Bresch D, Spiegel A (2010) Insurance as an Adaptation Option Under UNFCCC. In: Background Paper; Swiss Federal Office for the Environment

Sharoff J, Diro RL, McCarney G, Norton M (2012) R4 Rural Resilience Initiative in Ethiopia. Climate Services Partnership. [http://www.climate-services.org/ content/r4-rural-resilience-initiative-ethiopia]

Thomson MC, Doblas-Reyes FJ, Mason SJ, Hagedorn R, Connor SJ, Phindela T, Morse AP, Palmer TN (2006) Malaria early warnings based on seasonal 
climate forecasts from multi-model ensembles. Nature 439:576-579

Thomson MC, Zadravecz F, Lyon B, Mantilla G, Willis D, Ceccato P, Dinku T (2012) Development of Climate Analysis Section for the President's Malaria Initiative Impact Evaluation: Reports for Ethiopia and Tanzania. President's Malaria Initiative-USAID Report

Vancutsem C, Ceccato P, Dinku T, Connor SJ (2010) Evaluation of MODIS Land surface temperature data to estimate air temperature in different ecosystems over Africa. Remote Sens Environ 114:449-465

Washington R, Harrison M, Conway D, Black E, Challinor A, Grimes D, Jones R, Morse A, Kay G, Todd M (2006) Africa climate change: Taking the short route. Bull Am Meteorol Soc 87:1355-1366

WHO/UNICEF (2013) The World Malaria Report 2012. Geneva

World Bank (2011) Weather Index Insurance for Agriculture: Guidance for Development Practitioners. Washington

http://modis.gsfc.nasa.gov/.

http://www.ethiomet.gov.et/.

http://iridl.ldeo.columbia.edu.

http://www.oxfamamerica.org/explore/research-publications/copy_of_r4-ruralresilience-initiative-2/.

http://iri.columbia.edu/wiiet.

http://iridl.ldeo.columbia.edu/maproom/.

doi:10.1186/2194-6434-1-15

Cite this article as: Dinku et al:: Bridging critical gaps in climate services and applications in africa. Earth Perspectives 2014 1:15.

\section{Submit your manuscript to a SpringerOpen ${ }^{\circ}$ journal and benefit from:}

- Convenient online submission

- Rigorous peer review

- Immediate publication on acceptance

- Open access: articles freely available online

- High visibility within the field

- Retaining the copyright to your article

Submit your next manuscript at $\gg$ springeropen.com 